\title{
Kernos
}

Revue internationale et pluridisciplinaire de religion grecque antique

$30 \mid 2017$

Varia

\section{Sacrum facere}

\section{Hélène Collard}

\section{OpenEdition \\ Journals}

\section{Édition électronique}

URL : http://journals.openedition.org/kernos/2548

DOI : 10.4000/kernos.2548

ISSN : 2034-7871

\section{Éditeur}

Centre international d'étude de la religion grecque antique

\section{Édition imprimée}

Date de publication : 1 octobre 2017

Pagination : 359-360

ISSN : 0776-3824

Référence électronique

Hélène Collard, «Sacrum facere », Kernos [En ligne], 30 | 2017, mis en ligne le 01 octobre 2017, consulté le 24 septembre 2020. URL : http://journals.openedition.org/kernos/2548; DOI : https:// doi.org/10.4000/kernos.2548

Ce document a été généré automatiquement le 24 septembre 2020.

Kernos 


\title{
Sacrum facere
}

\author{
Hélène Collard
}

\section{RÉFÉRENCE}

Sacrum facere, Atti del I Seminario di Archeologia del Sacro (Trieste, 17-18 febbraio 2012), Trieste, Edizioni Università di Trieste, 2013.1 vol. $17 \times 24 \mathrm{~cm}$, viII+296 p.

(Polymnia. Studi di archeologia, 5). ISBN : 978-88-8303-507-4.

Federica FONTANA, Emanuela MURGIA (éd.), Sacrum facere. Contaminazioni: forme di contatto, traduzione e mediazione nei sacra del mondo greco e romano, Atti del II Seminario di Archeologia del Sacro (Trieste, 19-20 aprile 2013), Trieste, Edizioni Università di Trieste, 2014. 1 vol. $17 \times 24 \mathrm{~cm}$, VIII+332 p. (Polymnia. Studi di archeologia, 6). ISBN : 97888-8303-576-0.

Federica FONTANA, Emanuela MURGIA (éd.), Sacrum facere. Lo spazio del 'sacro': ambienti e gesti del rito, Atti del III Seminario di Archeologia del Sacro (Trieste, 3-4 ottobre 2014), Trieste, Edizioni Università di Trieste, 2016. 1 vol. $17 \times 24 \mathrm{~cm}$, XII+491 p. (Polymnia. Studi di archeologia, 7). ISBN : 978-88-8303-679-8.

1 Si l'étude des lieux de culte a depuis toujours retenu l'attention des archéologues, ces dernières décennies ont $\mathrm{vu}$ se développer un intérêt croissant pour la notion d' " espace sacré » au sens large - c'est-à-dire selon une démarche qui prenne en considération tous les témoignages, spatiaux et matériels, pouvant relever de la sphère du sacré -, et ce suivant une approche interdisciplinaire faisant dialoguer étroitement archéologie et anthropologie religieuse. C'est dans la même dynamique de réflexion que s'inscrit l'ambitieux programme "Sacrum facere", mis sur pied par Federica Fontana à l'Université de Trieste. Celui-ci prend la forme, depuis 2012, de séminaires annuels, actuellement au nombre de cinq. Les trois ouvrages présentés ici rassemblent les actes des trois premières rencontres; les deux dernières - tenues respectivement en 2015 et 2016 sur les thèmes "Le figure del 'sacro': divinità, ministri, devoti" (IV Seminario) et "Sacra peregrina: la gestione della pluralità religiosa nel mondo antico" (V Seminario) - attendent encore d'être publiées. Alors que le premier volet abordait 
la thématique de façon assez générale, les quatre suivants portent donc sur des thèmes et des questionnements plus précis.

2 Il n'est pas question de rendre compte dans le détail de chacun des 44 articles qui composent ces trois volumes, d'autant que très peu d'entre eux finalement concernent directement le monde grec (est surtout prise en considération la péninsule italique, avec quelques incursions en Grèce propre et en Anatolie). Chaque volume s'ouvre sur une préface, puis sur une contribution de F. Fontana, qui tiennent lieu d'introduction en posant de façon adéquate les problématiques et les prémices de chacune des rencontres. Suivent ensuite l'ensemble des contributions particulières, sans aucun ordonnancement apparent, ce qui peut laisser une impression d'incohérence et de discontinuité au sein d'ouvrages collectifs abordant une thématique d'une telle ampleur. Il n'en reste pas moins que l'ensemble des études est d'excellente qualité, tant sur le fond que pour la méthode, certaines d'entre elles apportant un réel renouvellement interprétatif.

3 On saluera donc l'entreprise, fructueuse, qui viendra sans aucun doute renouveler et consolider notre connaissance de la topographie et de la culture matérielle des polythéismes antiques. Pour terminer, les ouvrages sont bien édités et bien illustrés (nombreuses planches, en noir et blanc et en couleurs), et mentionnons enfin la présence, pour chacun d'entre eux, de vraies conclusions générales, rédigées par un spécialiste de l'archéologie et/ou des questions religieuses, ce qui est trop rare dans ce type de volumes collectifs.

\section{AUTEURS}

HÉLÈNE COLLARD

F.R.S.-FNRS - Université de Liège 